\title{
LA REGULACIÓN JURÍDICA DE LA TRANSFORMACIÓN DE LA CIUDAD
}

\author{
Enrique Bardají Álvarez (Arquitecto - Profesor Ad Honorem DUyOT)
}

Tengo para mí que nuestra disciplina, o mejor su aplicación práctica, no pasa por momentos fáciles. La regulación de lo que deba ser la ciudad o la intervención física en ella, se perciben por el "pensamiento colectivo publicado dominante" como actividades envueltas con el oscuro velo de lo turbio.

No siempre fue así. El conjunto de determinaciones técnicas y artísticas que exigía el crecimiento de las ciudades del XIX, iniciaron el cuerpo teórico del urbanismo y aun respondiendo a corrientes de la historia más o menos generosas con unos grupos sociales u otros, no fueron consideradas en su época como actividades de inmorales cuando no delincuentes. El conjunto de conocimientos relativos a la planificación, desarrollo, reforma y ampliación de los edificios y espacios de las ciudades que conocemos como urbanismo, perseguía la mejora de la vida de los ciudadanos.

Tanto en los planes de ensanche como en los de reforma interior, el peso del trazado (el plano) y las sucintas normas jurídicas que lo acompañaban orientaban el peso de la intervención en la ciudad hacia la resolución de los problemas técnicos (abastecimientos de servicios, eliminación de residuos, organización de la movilidad, etc...) y de los artísticos (caracterización del espacio público y de los edificios). Sin duda que la importancia de la propiedad del suelo y de su transformación económica condicionaba los trazados, pero no con la contundencia que hoy lo hace. El objetivo reconocido del urbanismo era la organización del futuro de la ciudad para la mejor vida en ella de los ciudadanos. El planeamiento perdió ya hace unos años (me atrevo a decir que al menos, desde la Ley de 1977) el objetivo que lo engendró como disciplina. Cada vez de forma más intensa, parece que el urbanismo español se sustancia por, al menos, tres circunstancias que lo han hecho complejo e ineficaz.

El primer aspecto que configura el urbanismo en España es la fijación del contenido del derecho inmobiliario de la propiedad como valor primordial, quedando como valores accesorios la viabilidad técnica, la razonabilidad económica, los principios culturales a potenciar o proteger, la belleza de la ciudad o el bienestar de los ciudadanos. No es que las exposiciones de motivos de las Leyes del Suelo o las Memorias de los Planes no hagan referencia y persigan objetivos en relación con los valores expuestos, sino que los textos normativos concretos están dirigidos, fundamentalmente, a describir con prolijidad (en cualquiera de sus acepciones admitidas incluida la de "impertinente, pesado, molesto") todos los mecanismos que hagan del planeamiento un instrumento para determinar cómo se benefician (o perjudican) de la transformación y el crecimiento de la ciudad cada uno de los propietarios registrales de la misma.

A esta regulación garantista del derecho de la propiedad del suelo se le suma la voluntad de describir y reglamentar con Leyes y Normas los procesos que permiten hacer realidad construida lo proyectado (procedimientos tecnológicos, ambientales, económicos, jurídicos, patrimoniales, etc...). Sin embargo, cada uno de estos procesos 
contiene especificidades diversas que la norma ha regulado desde sí mismos, convirtiendo cada subproceso en un cuerpo "científico" completo que se autoalimenta permanentemente sin considerar, con suficiente énfasis, su interrelación con otros procesos igualmente presentes en la formación de la ciudad.

Y si todo ello no fuera suficiente, en España, una absurda deriva identitaria y cantonalista ha permitido que mucho de lo particularísimo haya sido entendido como sustantivo, dando lugar a diferentes y pequeñas variaciones sobre los principios comunes que no hacen sino complicar más el campo regulatorio de la intervención en la ciudad generando no solo 17 Leyes diferentes del Suelo en un único Estado sino innumerables interpretaciones, modificaciones y variaciones de cada una de dichas Leyes. Y lo más grave, en mi opinión, es que estas orientaciones han argumentado perseguir (positivando cada acción sobre la ciudad como imprescindible para su regulación) un principio básico e irrenunciable del Estado de Derecho que es la "seguridad jurídica" como expresión del "ius gentium", derecho que el progreso de la civilización ha obtenido para los ciudadanos, superando el "ius naturale".

Sin embargo, creo que la plasmación jurídica del urbanismo español ha conseguido, por dispersión, opacidad, incorrección en la técnica jurídica de la regulación de técnicas científicas y contradicción entre normas, una gran "inseguridad jurídica". Esta orientación de nuestra normativa urbanística ha hecho de ella un farragoso Corpus Legal inescrutable. El conjunto de protocolos que se deducen de las infinitas normas existentes es inmanejable y solo se materializa en actos físicos concretos de intervención en la ciudad cuando se conculcan (invito a que se me presente cualquier intervención física en la ciudad de la que no pueda señalar un pequeño o gran incumplimiento de alguna de las normas que la regulan). Por ello intervenir en el planeamiento (como instrumento del urbanismo) es hoy una actividad propia de "espeleólogos jurídicos" que se adentran en la procelosa caverna de la Norma Urbanística deduciendo de sus infinitos vericuetos interpretaciones discutibles (y discutidas), que dificultan extraordinariamente la pacífica intervención en la ciudad. Los procesos de inmersión en la Norma Urbanística han dado cuerpo a un mundo profesional que ha legitimado con sus "hallazgos normativos" verdaderas conculcaciones de la Razón y, sin duda, ha creado el caldo de cultivo adecuado para la corrupción.

Podría deducirse, erróneamente, de las frases anteriores que preconizo la desaparición de la regulación normativa en las actuaciones sobre la ciudad. Nada más alejado de mi posición que la vuelta a una inexistencia de regulación de carácter medieval. Sin embargo, la situación actual es la Ley de la Selva, escondida, eso sí, bajo una regulación positiva que parece conceder a la Normativa Urbanística una honorabilidad jurídica de la que, en su conjunto, carece.

La superación de esta situación solo puede caminar por las reformas legales que unifiquen, coordinen, simplifiquen y prioricen aquellos objetivos que desde sus inicios ha perseguido el Urbanismo y que, con mayor o menor éxito, enseñamos en nuestras Universidades. La claridad es un elemento imprescindible (bien que no el único) para alcanzar una auténtica "seguridad jurídica". La marea política regeneracionista de nuestras Instituciones que las circunstancias históricas han desencadenado en nuestro país, debe incluir en su agenda la regeneración del Corpus Legal Urbanístico. Es el momento. 